\title{
The 6M approach to land subsidence
}

\author{
Gilles Erkens $^{1,2}$ and Esther Stouthamer ${ }^{2}$ \\ ${ }^{1}$ Deltares Research Institute, Daltonlaan 600, 3584 BK, Utrecht, the Netherlands \\ ${ }^{2}$ Faculty of Geosciences, Utrecht University, $3584 \mathrm{CB}$, Utrecht, the Netherlands \\ Correspondence: Gilles Erkens (gilles.erkens@deltares.nl)
}

Published: 22 April 2020

\begin{abstract}
Though global awareness of land subsidence has increased over recent years, subsidence remains an ongoing and largely unsolved problem, which is exemplified by frequent discoveries of apparently new subsiding areas. This means that for many of these areas there is a continuous and growing need to provide guidance to decision makers on how to tackle this global problem. This paper presents a comprehensive, step-by-step approach to address land subsidence, illustrated by best practise examples from around the world. The approach places emphasis on the long-term sustainability of resources, whose development is related to the subsidence problems. We identified 6 steps, collectively referred to as the $6 \mathrm{M}$ approach, that are crucial to tackle subsidence: Measuring, understanding Mechanisms, Modelling, Money, Measures and Monitoring. This paper offers guidance for implementing the $6 \mathrm{M}$ approach, and the lessons learned from the real-life examples provide valuable information and inspiration for decision makers and experts to address subsidence. The focus is on subsidence in deltaic and coastal areas where subsidence contributes to relative sea level rise. It is expected that the $6 \mathrm{M}$ approach will contribute to lowering the threshold to act on subsidence. The $6 \mathrm{M}$ approach is also used as a guiding principle for the thematic subdivision of TISOLS, providing a meaningful linkage between subsidence science and the societal response to subsidence problems.
\end{abstract}

\section{Introduction: land subsidence, a wicked problem}

In many coastal and delta cities land subsidence exceeds absolute sea level rise, in some places as much as a factor of ten (e.g. Erkens et al., 2016a). Increased flood risk and other widespread impacts of subsidence result in damage totalling billions of dollars per year (Bucx et al., 2015, 2019). Much of this land subsidence is caused by human activities, such as groundwater extraction or draining and loading of soft soils (e.g. Galloway et al., 2016). Addressing subsidence in these vulnerable coastal areas has proven to be challenging. Generally, land subsidence is a slowly progressing, hidden threat, often not leading to a sense of urgency. In many cases, technical options to mitigate and adapt to subsidence are readily available, but formulating a subsidence strategy is difficult, let alone implementing its strategic measures. This is because land subsidence presents complex technical and societal issues involving many stakeholders with wide-ranging interests, and generally poor technical understanding of the underlying processes (Bucx et al., 2019). This paper offers guidance in the form of a step-wise 6M approach to help overcome these impediments to deal with land subsidence.

\section{The land subsidence lock-in}

Throughout history, in coastal areas adaptation to land subsidence has been the preferred strategy to manage subsidence hazards. For instance, the raising of embankments has traditionally been the response to lowered land elevations and the consequent increased flood risk. Subsidence that resulted in reduced drainage capacity of the surface water and overall wetter conditions, has often been addressed by the installation of pumps, which led to further subsidence (e.g. Erkens et al., 2016b for the Dutch situation). There are sparse examples of subsidence mitigation measures from the past. In fact, it was not until the 1960s that the first mitigation measures were taken (Bucx et al., 2015). The dominance of experiences with adaptation measures have led to an optimisation of subsidence adaptation strategies. This applies to the technical aspects (for example, the building of embankments for 


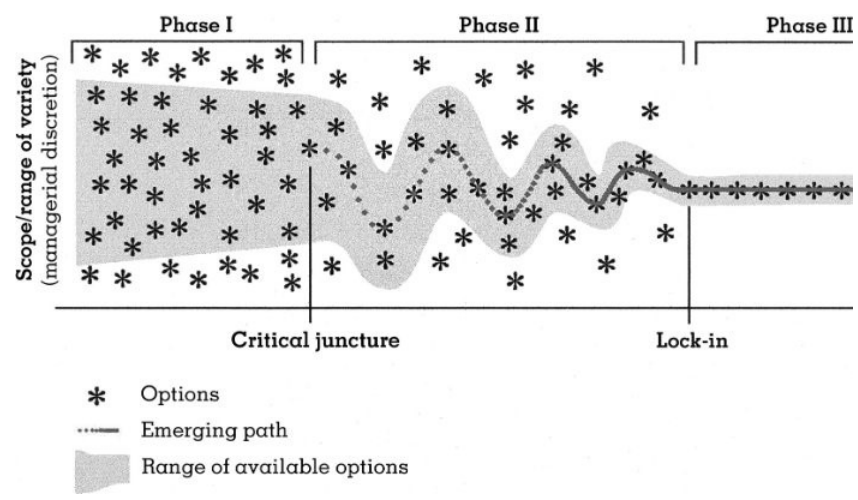

Figure 1. Path dependency leads to a lock-in situation at the end. This is currently the situation for land subsidence in many coastal areas, where an adaptation strategy is preferred over a mitigation strategy (The constitution of an organisational path figure from Sydow et al., 2009).

flood protection and pumping stations that drain the land), but also to the institutional and financial aspects. Institutions that have implemented these adaption measures and strategies have strengthened as they have acquired the requisite technical skills and knowledge, and the necessary vast financial resources (Seijger et al., 2018). As a result, over time it was increasingly easy to implement an adaptation strategy to subsidence problems. This development of a single strategy to manage subsidence problems, can be viewed as a path-dependent process, where future managerial discretion in terms of choices or options depends on the choices made in the past (Fig. 1). The end stage of path dependency, when managerial discretion is limited and a single management option is fully dominating, is called a lock-in. Sinking coastal and deltaic areas can thus be regarded as being trapped in a dual lock-in condition as the dominating adaptation strategy in terms of the applied technologies and the principal institutions act as constraints to moving toward a more long-term sustainable strategy (Seijger et al., 2018), one that may also include measures to mitigate subsidence.

\section{Emerging from the lock-in}

The lock-in condition means that it is difficult to choose alternative management options, as this conflicts with existing interests and breaks with the long-standing traditional approach to managing the subsidence. If the societal and financial benefits of alternative management approaches are fully known, a different action perspective may be proffered to decision makers. For these management alternatives a sound and shared knowledge base is required in terms of an indepth understanding of the physical problems, the financial perspectives (what are the costs and benefits of different options?) and governance and legal capabilities (who is responsible and are there sufficient capabilities to implement the management measures?). When these conditions are satisfied, the threshold to act on an alternative management strategy will become lower.

Emerging from the lock-in is becoming increasingly urgent in subsiding coastal and deltaic areas. On the one hand, awareness of subsidence and its consequences has increased, exemplified by increased media coverage and scientific studies over the recent years. On the other hand, the sense of urgency has increased because as land subsidence accumulates, new problems arise, and existing problems worsen. Exposure to land subsidence is also still increasing, as population growth, ongoing urbanisation and economic growth seems to be focussed in coastal and deltaic areas. Finally, the realisation that land subsidence is interconnected with absolute sea level rise, both contributing to relative sea level rise, and the increasingly grim predictions of future climate warming induced absolute sea level rise increase the urgency to deal with subsidence in coastal and deltaic areas. In this light, land elevation needs to be viewed as an economic asset, and therefore loosing elevation as a liability.

\section{A strategic framework}

Realising that a sound and shared knowledge base is required to facilitate decision making to emerge from the lock-in, the question of where to start arises. Bucx et al. (2015) gathered real-life examples of best practises from around the world where land subsidence has been addressed. This was further elaborated and put into a framework by Erkens et al. (2015). Over the last years, the framework has evolved to what is presented in this paper: 6 steps that need to be taken to facilitate decision making with scientific knowledge. In contrast to many existing studies that describe how knowledge may be used in decision making (for instance Van Hardeveld, 2019 for land subsidence in the Netherlands), this study uses examples to document how this is done in practise and is therefore more anecdotal.

A step-wise approach is elaborated along the stages of the policy cycle, with clear steps that need to be taken (Fig. 2). The policy cycle is a tool that is used to analyse the development of a policy item and has been used for decades in political sciences. For each of the steps identified, there are questions that need to be addressed, and commonly both technical and governance aspects need to be considered to answer the questions. Because the steps are sequential, they offer a stepwise path on how to proceed. In total 6 steps were identified that provide the required information when starting to tackle subsidence, that all include the letter $\mathrm{M}$ (hence the $6 \mathrm{M}$ approach, Fig. 2): Measuring of land subsidence, understanding land subsidence Mechanisms, predictive Modelling of land subsidence, Monetary aspects of land subsidence (costbenefit analyses [CBA]), implementation of Measures, and Monitoring and evaluation. Although these steps are meant to be sequential, in real life short-cuts are being taken be- 


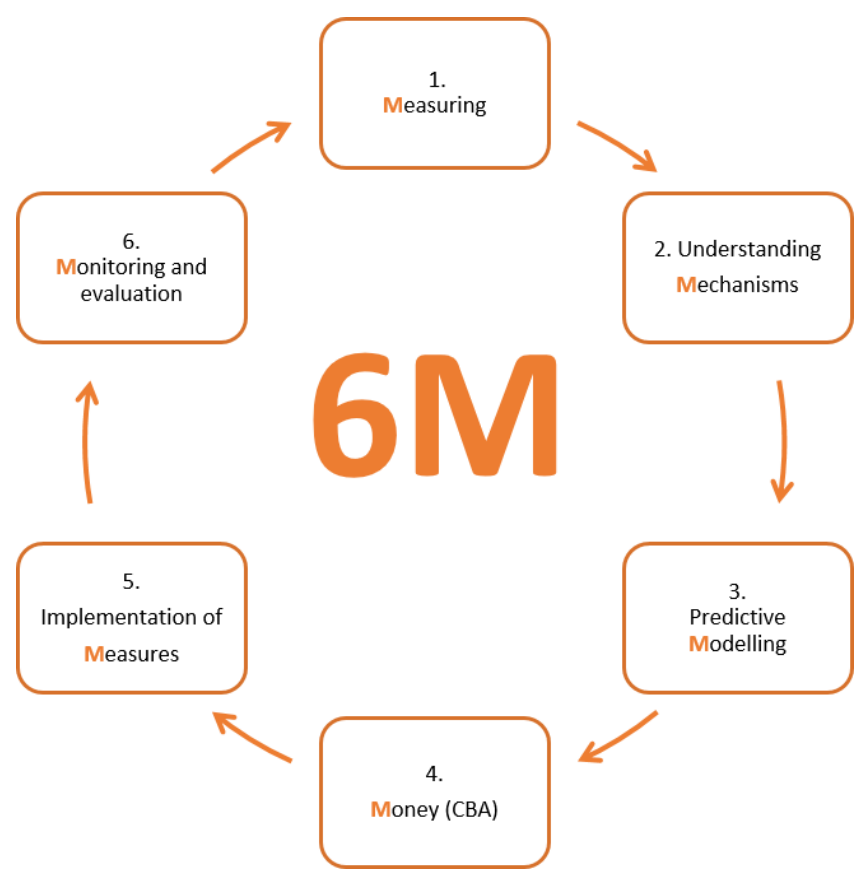

Figure 2. The $6 \mathrm{M}$ approach to land subsidence. The six steps are meant to be taken sequentially in a repeating loop, if necessary. $\mathrm{CBA}=$ cost benefit analyses. Image design by Welmoed Visser.

tween different steps, for instance when measurements (M1) from the first step show the urgency of the situation and measures are directly implemented (M5). If measures are proposed (M6) inspired by a best practise example elsewhere, sometimes the steps (Fig. 2) are followed in reverse order, specifically when locally-based substantiation is required to justify proposed measures.

Once the circle of the 6M approach is completed and monitoring and evaluation is in place, it is likely that evaluation leads to new research questions and the 6Ms start over. To ensure application of the gathered knowledge in other areas or for other sources of subsidence, preferably the monitoring data, analytical results and best practice examples (of the various $6 \mathrm{M}$ steps) are stored in a central database.

\section{The 6M approach and TISOLS}

The 6M approach is also used as a guiding principle for the thematic subdivision of TISOLS, providing a meaningful linkage between subsidence science and the societal response to subsidence problems.

\section{Real-life examples of the 6 M's}

\subsection{M1 Measuring land subsidence}

In coastal or deltaic areas where there is no apparent indication of subsidence, the first step (M1) is to establish whether a certain area is in fact subsiding and if so, at what rate. The occurrence of subsidence may not be obvious from casual observation, particularly when subsidence is non-differential and no structural damage (cracks, tilting) is observed in buildings or infrastructure. Typically, the loss of elevation compared to local sea level is mistaken for sea level rise as a result of climate warming. The aim of the measurements is to obtain insight into the current status of the land subsidence in terms of spatial and temporal trends. This may also include obtaining insight on the governance situation or the legal framework related to land subsidence.

An example where land subsidence measurements were the first step to establish the problem and create awareness is Jakarta in Indonesia. Land subsidence was recognized in 1926 in northern Jakarta from optical levelling, but first reports of subsidence-related impacts to infrastructure and flooding date from 1978 (Abidin et al., 2001). Dedicated land subsidence measurements started in the late 1990s with the installation of GPS stations by the Technical University of Bandung and resulted in research publications that basically served the academic community (Bucx et al., 2019). After Jakarta was hit by the most severe flooding in three centuries in 2007 when the seawall was overtopped during high tide and seawater flooded $40 \%$ of the city, awareness progressively grew among authorities that land subsidence posed a problem that required further measuring (Bucx et al., 2015).

In contrast to geodetic surveys typically consisting of sparse point measurements, such as the aforementioned GPS stations, remotely sensed LIDAR (light detection and ranging) and InSAR (Interferometric Synthetic Aperture Radar) images can provide spatially detailed ground displacement maps. InSAR images date back to the early 1990s and can now be used to establish subsidence rates and patterns since then. Application of this technique in soft soil areas is for the moment limited to the built-up environment, as a result of the need for stable reflectors (targets). Ideally, multiple observation techniques are combined, for instance absolute measurements from GPS and optical levelling can be combined with remotely sensed data, for example, the relative displacement measurements from InSAR. In this way, spatially resolved subsidence maps with respect to a global geodetic reference frame can be produced. Heuff et al. (2019) published the first operational nation-wide spatially resolved subsidence map of the Netherlands with absolute deformation rates based on Persistent Scatterer InSAR, GNSS and gravimetry measurements (https://bodemdalingskaart.nl/, last access: 26 January 2020). This map shows that a large part of the Netherlands is indeed subsiding (Fig. 3).

\subsection{M2 understanding subsidence Mechanisms}

Land subsidence may be the result of different contributing processes. Often there are both natural and human-induced causes for land subsidence at the same location. Discriminating between these different sources by understanding the underlying mechanisms is relevant as natural subsidence rates 


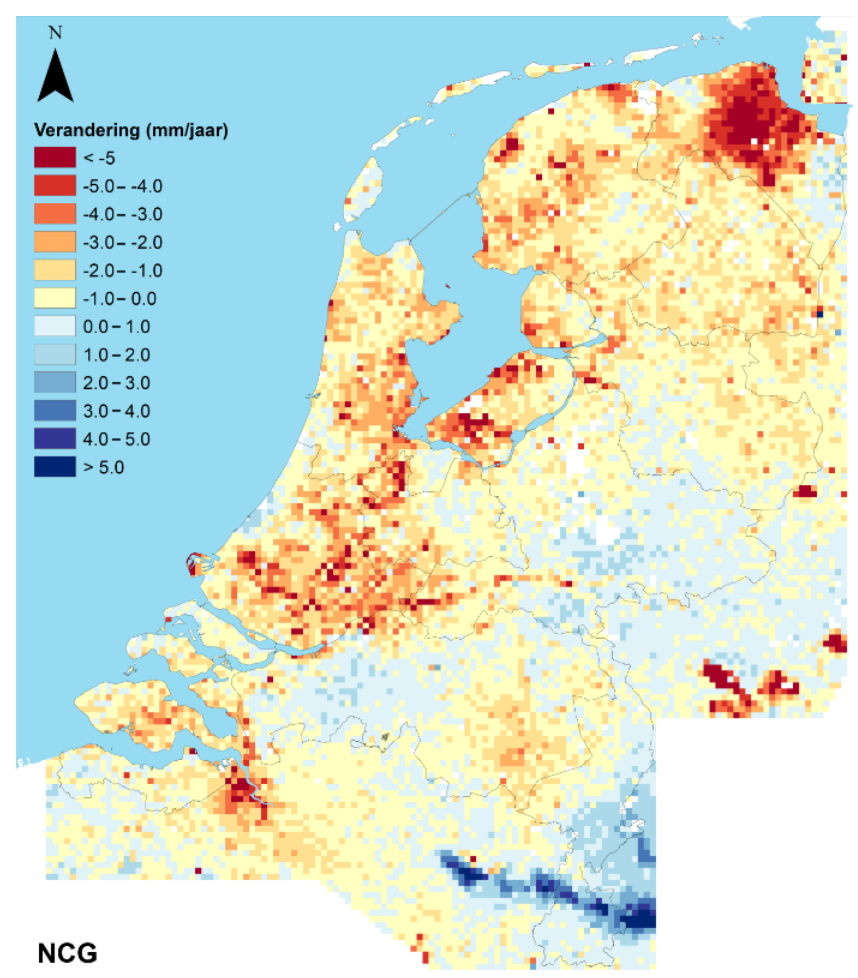

Figure 3. Land subsidence rates in the Netherlands (2015-2018). This product is an example where multiple measurement techniques were combined, in this case Persistent Scatterer InSAR, GNSS and gravimetry. Map downloaded in 2019 from https:// bodemdalingskaart.nl/ and produced by the Nederlands Centrum voor Geodesie en Geo-Informatica (Dutch Geodetic Centre, NCG). Verandering $(\mathrm{mm} / \mathrm{jaar})=$ Deformation $(\mathrm{mm} /$ year $)$.

are mainly limited to tens of mm per year. Human induced subsidence rates can easily reach $\mathrm{cm}$ 's per year, to even tens of cm's per year. For policy development this distinction between natural and human-induced subsidence is important: while it is worthwhile to implement mitigation measures to reduce human-induced subsidence, for natural subsidence only adaptation measures may be taken (Erkens et al., 2015).

Van Asselen et al. (2018) show that subsidence of streets and gardens in the Dutch urban area's on peat soils is the result of many different components, and that the contribution of these components may vary over time and space. In this example, in the urban areas the loading of the peat with anthropogenic fill is the dominant cause for the observed land subsidence. The oxidation of peat (biogeochemical process of soil organic matter decomposition by micro-organisms) is hampered because the peat has subsided below the groundwater level which is often situated within the fill (Fig. 4). Just outside the urban area, where the fill is absent, peat oxidation is the dominant factor causing subsidence. This shows that step M2 is relevant to select the right measure (M5): in this case raising the groundwater level would reduce subsidence by peat oxidation in the rural area but would be less effective in preventing subsidence in the urban area.

Unravelling components contributing to subsidence is essential to understand the underlying subsidence mechanisms. In-situ observations, for instance obtained with extensometers, may be used to unravel the total subsidence signal. Extensometers are used to measure compaction worldwide (e.g. Poland, 1984). Extensometers can be used to derive point measurements of vertical movement of different (sub)surface levels at mm-scale accuracy, and to determine the contribution of different layers, and in some cases processes, to total subsidence. Another approach that can be followed is inverse modelling, whereby with the use of a careful inversion scheme, the available knowledge on the geology and hydrological dynamics of a system can be quantitatively constrained with subsidence observations (e.g. Fokker et al., 2007). Observational data linked to a single subsidence process form essential input for step M3: subsidence modelling. This data may be used to validate process-based numerical subsidence models.

\subsection{M3 predictive Modelling of land subsidence}

In the third step M3, once the causes for land subsidence have been established, predictions can be made to gain insight into future land subsidence. Integrated land subsidence models that include multiple subsidence processes are still rare. Most numerical models describe a single land subsidence process, and there are in fact multiple models that predict compression of the subsurface soils and geologic materials, but all are focussed on applications at different depth ranges (for example, shallow soft soils, shallow to deep aquifer systems and deeper natural gas reservoirs).

An example where numerical modelling is used to predict future subsidence for different scenario's is the lowlying Mekong delta, largely located in Vietnam. As a first step (M1), Erban et al. (2014) used InSAR (Interferometric Synthetic Aperture Radar) to determine land subsidence rates of $10-40 \mathrm{~mm} \mathrm{yr}^{-1}$ between 2006-2010 over large areas in the Mekong Delta. Secondly (step M2), groundwater overexploitation has been proposed to be the main driver of subsidence in the Mekong Delta (Erban et al., 2014).

Thirdly (step M3), groundwater extraction-induced subsidence over the coming 80 years in the Mekong Delta was quantified using a numerical model (Minderhoud et al., 2020). The model consisted of two parts: a hydrological (groundwater) model (MODFLOW, USGS), and a oneway coupled geo mechanical land subsidence model SUBCR (Kooi et al., 2018). The groundwater model simulates groundwater drawdowns and extraction-induced subsidence in six mitigation and non-mitigation extraction scenarios on a delta-wide scale (Fig. 5). The model provided important insights. It shows the extent of lag effects in land subsidence after changes in the groundwater extraction. Important is the notion that if groundwater extraction is allowed to increase 


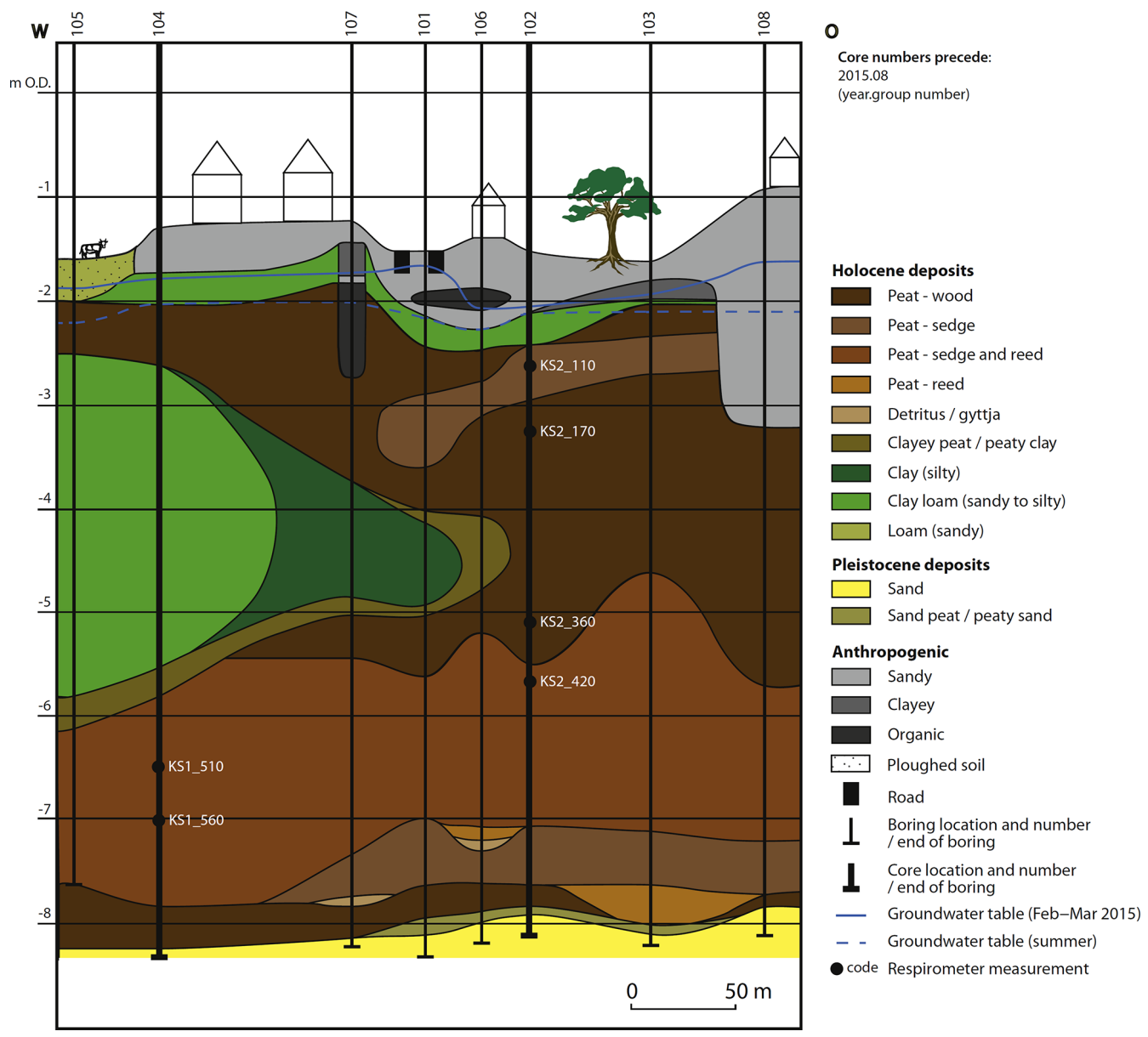

Figure 4. Cross-section from Van Asselen et al. (2018) showing that the groundwater level (blue line) is situated within the anthropogenic fill (coloured grey). This means that peat oxidation is limited in the urban area. Ouside the urban area, at the left end of the picture, the groundwater level is in the peat (coloured brown). Here, peat oxidation is the dominant process causing subsidence.

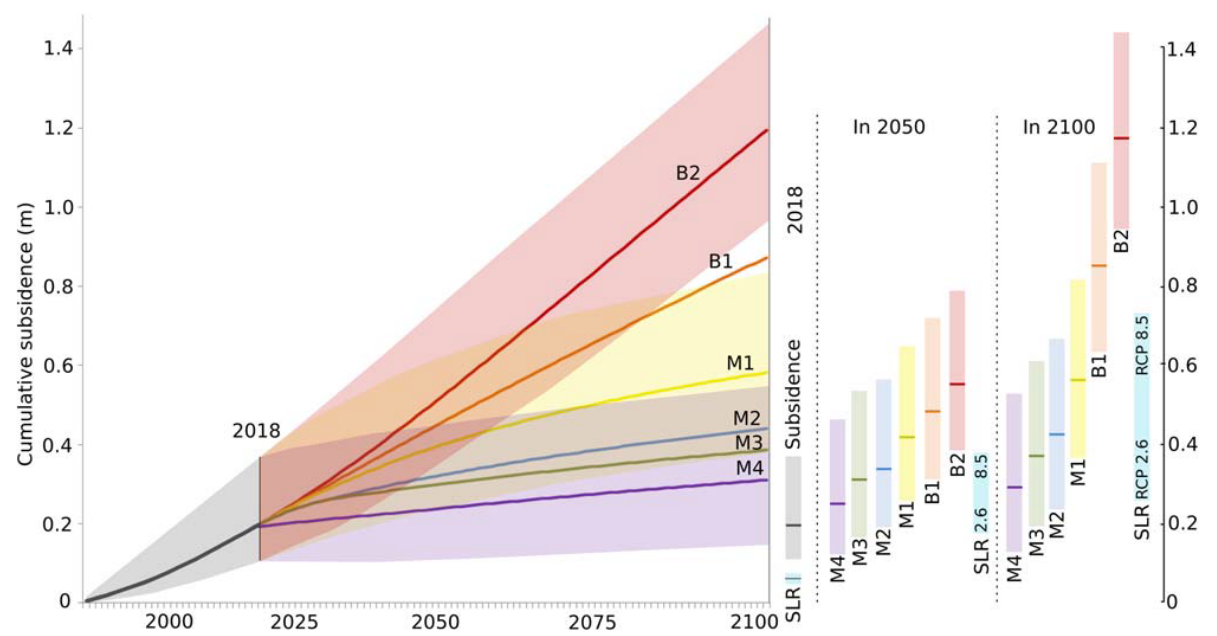

Figure 5. Average cumulative subsidence of the Mekong delta for different groundwater extraction pathways since 2018 (from Minderhoud et al., 2020). This modelling study shows the potential of limiting subsidence when more mitigative pathways are followed (scenarios M1-4 in the figure). 
continuously, as it did over the past decades, extractioninduced subsidence has the potential to drown the Mekong delta before the end of the century (Minderhoud et al., 2020). A positive note is that the outcomes also reveal the potential for mitigation measures to reduce subsidence by limiting groundwater exploitation (Fig. 5).

Modelling of land subsidence has some important added value compared to subsidence measurements. As useful as the InSAR measurements may be, the data only cover parts of the delta because of the paucity of stable reflectors in the rural areas. Model outcomes for historical scenario's (also for eras predating measurements) do provide spatially resolved insights and may be used in conjunction with InSAR results (e.g. Minderhoud et al., 2017). Furthermore, interpolation of measurements to retrieve future scenarios of land subsidence is not producing accurate results, as the spatial heterogeneity of the delta subsurface and variability in the hydrogeological situation, remain unaccounted for. Temporal variations in extraction amounts and more complex scenarios that include relocation of groundwater extractions throughout the delta can never be captured by simply extrapolating current observed rates. More refined modelling can provide the required spatially resolved subsidence predictions under various possible and realized future conditions.

\subsection{M4 Monetary aspects of land subsidence}

With subsidence predictions for different management scenarios available (M3), the next step is that for each scenario the cost (damage) and benefits (usually avoided damage/costs) need to be established as part of a cost-benefit analysis. Estimating subsidence-related costs is notoriously complex. Subsidence is a "hidden threat" because in practice, the actual costs appear on financial sheets as ad hoc investments or planned maintenance schemes but typically are not identified as damage costs related to subsidence (Erkens et al., 2015). Dedicated damage estimates can help to raise awareness among policymakers and initiate policy development. For subsidence, being a gradual process, usually mitigation measures are costly in the short term, but costeffective only in the long term (Erkens et al., 2015). Costbenefit analyses could provide insight into these hidden costs and potential benefits of mitigation measures in a quantitative way.

A recent example where a cost-benefit analyse was executed is the city of Gouda in the Netherlands (Kok, 2017). The historic city centre of Gouda is subsiding by approximately $3-5 \mathrm{~mm} \mathrm{yr}^{-1}$. Many older historical buildings have shallow foundations and subside at similar rates. Damp conditions and groundwater flooding in these buildings necessitated a repeated lowering of the groundwater level over the last centuries. Further lowering of the groundwater level however, might cause rotting of wooden foundations of buildings elsewhere in the city. This balance between damage costs to buildings with a shallow foundation and build- ings with a wooden pile foundation is reflected in the costbenefit analyses (Kok, 2017). The results show that in the reference scenario (business as usual), where groundwater levels are further lowered in the future, the expected damage costs from subsidence is between EUR 26-40 million before 2100. These are costs incurred to replace the wooden pile foundations that rot and to mitigate subsidence in the public space. If the groundwater level is not lowered, approximately EUR 4-11 million of these damage costs to wooden pile foundations may be prevented, but the damage costs due to the expensive reconstruction of shallow foundations add up to a disproportionate EUR 130 million. An alternative scenario, in which the groundwater levels would still be lowered, but at the same time measures are implemented to reduce the damage at the structures would cost EUR 7-16 million. However, the prevented damage in this scenario is approximately EUR 13-20 million, making this the economically most rational option.

This example shows how cost-benefit analyses, based on subsidence model outcomes, may inform decision makers, helping them to unlock the lock-in. It also provides a rationale for investing upfront in measures to realize long-term benefits. However, from a political perspective, this has the potential disincentive of incurring costs under one political administration only to have the benefits realized under another administration. Lastly, it shows how costs and benefits are different for different stakeholders. In the example above in the different scenarios, the costs and benefits are different for the owners of buildings with shallow foundation and the owners of buildings with wooden pile foundations. This may thus lead to demands for financial compensation measures or mitigative measures to be enforced to reduce costs for a certain stakeholder group.

\subsection{M5 implementation of Measures}

Implementation of measures follows cost-benefit analyses and the informed decision making. Implementation of measures often include governance and legal aspects (who is responsible?) and financial aspects (who is paying for the measures, and who is gaining the benefits?).

There are generally two policy strategies for subsiding areas: mitigation and adaptation - analogue to climate change policy discussions. A successful strategy, however, probably includes both (Erkens et al., 2015). Mitigation only works for human-induced subsidence (see M2). For the human-induced subsidence that cannot be mitigated, owing either to technical difficulties, or to financial constraints (i.e. the mitigation costs are too high), an adaptation strategy should be considered. This is also true for latent or lagging subsidence (see M3) occurring after a particular set of mitigation measures have been implemented or for natural subsidence, for which mitigation does not apply. Whereas mitigation focusses on the hazard element within the risk equation, adaptation measures focus on reducing the impact of subsidence, by decreas- 
ing the vulnerability of a certain asset to the negative impacts of subsidence and/or by decreasing the exposure of assets to subsidence.

For most cities that pursue an active policy on subsidence, mitigation measures are uncommon, but successful examples do exist. The examples of Tokyo (Japan) and Bangkok (Thailand) provide an interesting contrast (Erkens et al., 2015). In Tokyo, land subsidence was arrested after strict regulations restricting groundwater use were implemented. The restrictions started from the early 1950s and were subsequently extended to a larger area and to a larger group of stakeholders. This gave stakeholders time to adjust and to develop alternative water sources. For instance, surface water availability was enhanced as dams were constructed in several river basins that were designated for water resources development. In Bangkok, Thailand, regulation of groundwater extraction have successfully reduced the land subsidence. A main element of the measures was the taxation of groundwater use. Groundwater-use charges were first implemented in 1985 and have gradually increased. In Bangkok, currently only about $10 \%$ of the total water use is derived from groundwater extractions, mainly for industrial use. Whereas Tokyo followed a path of restriction in a top-down way, Bangkok followed a path of self-regulation using taxation. It is encouraging to see that both strategies have worked and share some similarities. In both cases, the costs of the measures were high, and impacted households and businesses, alike. In both cities, the implementation of measures was accompanied by investing in development of databases containing measurement data (step M1) and predictive model outcomes (step M3). There were heavy investments in city-wide monitoring systems (step M6). Lastly, in both cases the federal government played an important role in the final decision making, bypassing the local decision-making structures.

\subsection{M6 Monitoring and evaluation of subsidence measures}

For all measures taken to reduce land subsidence and its impacts, it is important that the effectiveness of the measures is monitored. This implies that a subsidence monitoring network needs to be installed before the measures are implemented. Often, the monitoring network will be based on the same techniques or methods that was used to initially measure land subsidence (M1). Monitoring of the results of the implemented measures will enable the adjustment of these measures in due course.

Shanghai, China is an example of a city with a successful subsidence mitigation strategy and a robust operational monitoring system. The city has experienced severe land subsidence as a result of excessive groundwater extraction for domestic and industrial use (e.g. Ye et al., 2016a, b). Land subsidence in Shanghai was reported as early as 1921. Average subsidence rates since are approximately $26 \mathrm{~mm} \mathrm{yr}^{-1}$. In the 1960s, a series of countermeasures were taken (Ye et al., 2016a), including a resolution restricting groundwater use, the implementation of artificial recharge of groundwater, and the partial transfer of groundwater withdrawal to deeper aquifers. This resulted in decreased rates of land subsidence in the Shanghai urban area. Currently, the maximum allowed land subsidence in Shanghai is $6 \mathrm{~mm} \mathrm{yr}^{-1}$. If this is exceeded, extra measures are implemented, such as stricter restrictions on groundwater extraction amounts. Generally, the consequences of the (lower) land subsidence rates are considered acceptable, but additional subsidence mitigation measures may be implemented if required. An essential element of this strategy is the monitoring network. Land subsidence in Shanghai is traditionally monitored by means of extensometers, benchmarks and groundwater observation wells (Ye et al., 2016a). The oldest parts of the monitoring systems have been installed in the 1960 s to monitor the accelerating subsidence rates occurring at that time and have been operational ever since. Numerical land subsidence models supported the detailed mitigation measures implemented in Shanghai. Monitoring results are coevally used to continuously evaluate the performance of the subsidence mitigation strategy.

The city of Shanghai works with a safe level of land subsidence. The is the level of land subsidence at which the damage is still acceptable and perhaps compensable. The appointment of the acceptable remaining rates of subsidence and associated damage is foremost a policy issue, and heavily relies on accurate damage estimates (M4) which are often rare. But, the establishment of a "safe" level of land subsidence is a crucial step in mitigating and controlling subsidence. This level will most likely not be zero: a reasonable small amount of subsidence (geologically or naturally caused for instance) has to be accepted in all cases.

\section{Concluding remarks}

The 6M approach and framework fulfils two needs. On the one hand, it guides decision makers through steps that are required for informed decision making based on best practise examples from elsewhere. Land subsidence is a relative slow hazard, and is often considered an urgent, but not immediate threat. It therefore requires a long-term perspective, which this step-by-step framework offers. This framework may be applicable to implementing measures for other hazards as well.

On the other hand, the $6 \mathrm{M}$ approach provides scientists with an applied, uniform context for their research. By identifying subsidence research as a component of one or more of the 6 steps, researchers can better focus their research and more effectively compare, share and communicate results within the scientific community. It may also help in communicating scientific results to decision makers and stakeholders. Because this type of communication is a key element of the Tenth International Symposium on Land Subsidence in 
the Netherlands in 2021, the $6 \mathrm{M}$ framework is used as the guiding principle for the thematic subdivision of TISOLS.

Data availability. All data used in this review paper is published and available through the cited papers in the reference list.

Author contributions. GE designed the $6 \mathrm{M}$ approach, provided the literature review and wrote the paper. ES helped in further developing the research approach and tested the approach in practise

Competing interests. The authors declare that they have no conflict of interest. Gilles Erkens is member of the editorial board of this special issue but has not reviewed this paper, nor has he influenced the publication decision process.

Special issue statement. This article is part of the special issue "TISOLS: the Tenth International Symposium On Land Subsidence - living with subsidence". It is a result of the Tenth International Symposium on Land Subsidence, Delft, the Netherlands, 17-21 May 2021.

Acknowledgements. We sincerely thank Devin Galloway (United States Geological Survey) for his constructive comments on a draft version of this paper. During his time as chair of the UNESCO working group on land subsidence, Devin Galloway promoted to link land subsidence science to society and valued practical application of scientific results. Encouraged by this, this paper seeks to contribute to this science-policy interaction within the land subsidence community.

\section{References}

Abidin, H. Z., Djaja, R., Darmawan, D., Hadi, S., Akbar, A., Rajiyowiryono, H., Sudibyo, Y., Meilano, I., Kasuma, M. A., Kahar, J., and Subarya, C.: Land Subsidence of Jakarta (Indonesia) and its Geodetic Monitoring System, Nat. Hazards, 23, 365-387, 2001.

Bucx, T., Erkens, G., Dam, R., De Lange, G., and Lambert, J.: Sinking Cities, Deltares brochure, Delft, the Netherlands, 12 pp., 2015.

Bucx, T., Erkens, G., Hommes, S., Kok, S., Ellen, G. J., Kooi, H., and Van de Guchte, C.: Sinking cities II - example cases, Deltares brochure, Delft, the Netherlands, 25 pp., 2019.

Erban, L. E., Gorelick, S. M., and Zebker, H. A.: Groundwater extraction, land subsidence, and sea-level rise in the Mekong Delta, Vietnam, Environ. Res. Lett., 9, 084010, https://doi.org/10.1088/1748-9326/9/8/084010, 2014.

Erkens, G., Bucx, T., Dam, R., de Lange, G., and Lambert, J.: Sinking coastal cities, Proc. IAHS, 372, 189-198, https://doi.org/10.5194/piahs-372-189-2015, 2015.

Erkens, G., Bucx, T., Dam, R., De Lange, G., and Lambert, J.: Sinking Cities: An Integrated Approach to Solutions, in: The Making of a Riskier Future: How Our Decisions Are Shaping Future. Disaster Risk, edited by: Global Facility for Disaster Reduction and
Recovery, World Bank, Washington, D.C., USA, Case Study C 90-99, 2016a.

Erkens, G., van der Meulen, M. J., and Middelkoop, H.: Double trouble: subsidence and $\mathrm{CO}_{2}$ respiration due to 1,000 years of Dutch coastal peatlands cultivation, Hydrogeol. J., 24, 551-568, 2016b.

Fokker, P. A., Muntendam-Bos, A.-G., and Kroon, I. C.: Inverse modelling of surface subsidence to better understand the Earth's subsurface, First Break, 25, 101-105, https://doi.org/10.3997/1365-2397.25.1110.27601, 2007.

Galloway, D. L., Erkens, G., Kuniansky, E. L., and Rowland, J. C.: Preface: Land subsidence processes, Hydrog. J., 24, 547-550, 2016.

Heuff, F., van Leijen, F., Mulder, G., Samiei-Esfahany, S., and Hanssen, R.: Observations of Dutch Peat Soils during dry summer of 2018 and its consequences for $\mathrm{CO}_{2}$ emissions, Geophysical Research Abstracts, Vienna, Austria, 21, 1 p., 2019.

Kok, S.: Quick scan MKBA bodemdaling binnenstad Gouda, Deltares report, Utrecht, the Netherlands, 2017 (in Dutch).

Kooi, H., Bakr, M., de Lange, G., den Haan, E., and Erkens, G.: User guide to SUB-CR; a MODFLOW package for land subsidence and aquifer system compaction that includes creep, Deltares internal report 11202275-008, Utrecht, the Netherlands, 2018.

Minderhoud, P. S. J., Erkens, G., Pham, V. H., Bui, V. T., Erban, L., Kooi, H., and Stouthamer, E.: Impacts of 25 years of groundwater extraction on subsidence in the Mekong delta, Vietnam, Environ. Res. Lett., 12, 064006, https://doi.org/10.1088/17489326/aa7146, 2017.

Minderhoud, P. S. J., Middelkoop, H., Erkens, G., and Stouthamer, E.: Groundwater extraction may drown mega-delta: projections of extraction-induced subsidence and elevation of the Mekong delta for the 21st century, Environ. Res. Commun., 2, 011005, https://doi.org/10.1088/2515-7620/ab5e21, 2020.

Poland, J. F.: Guidebook to Studies of Land Subsidence Due to Ground-water Withdrawal, UNESCO report, Paris, France, ISBN 92-3-102213-X, 1984.

Seijger, C., Ellen, G. J., Janssen, S., Verheijen, E., and Erkens, G.: Sinking deltas: trapped in a dual lock-in of technology and institutions, Prometheus, 35, 193-213, 2018.

Sydow, J., Schreyögg, G., and Koch, J.: Organisational Path Dependence: Opening the Black Box, Acad. Manage. Rev., 34, 689709, 2009.

Van Asselen, S., Erkens, G., Stouthamer, E., Woolderink, H. A. G., Geeraert, R. E. E., and Hefting, M. M.: The relative contribution of peat compaction and oxidation to subsidence in built-up areas in the Rhine-Meuse delta, The Netherlands, Sci. Total Environ., 636, 177-191, 2018.

Van Hardeveld, H.: Informed science-policy interactions: Advancing the support of collaborative management of social-ecological systems, PhD thesis, Utrecht University, Utrecht, the Netherlands, 170 pp., 2019.

Ye, S., Xue, Y., Wu, J., Yan, X., and Yu, J.: Progression and mitigation of land subsidence in China, Hydrogeol. J., 24, 685-693, 2016a.

Ye, S., Luo, Y., Wu, J., Yan, X., Wang, H., Jiao, X., and Teatini, P.: Three-dimensional numerical modeling of land subsidence in Shanghai, China, Hydrogeol. J., 24, 695-709, 2016 b. 